\title{
Union of the Comoros: Interim Poverty Reduction Strategy Paper- Joint Staff Advisory Note
}

The attached Joint Staff Advisory Note (JSAN) of the Interim Poverty Reduction Strategy Paper for the Union of the Comoros, prepared jointly by the staffs of the World Bank and the IMF, was distributed with the member country's Interim Poverty Reduction Strategy Paper (PRSP) to the Executive Boards of the two institutions. The objective of the JSAN is to provide focused, frank, and constructive feedback to the country on progress in implementing its Poverty Reduction Strategy (PRS).

To assist the IMF in evaluating the publication policy, reader comments are invited and may be sent by e-mail to publicationpolicy@imf.org.

Copies of this report are available to the public from

International Monetary Fund • Publication Services

$70019^{\text {th }}$ Street, N.W. • Washington, D.C. 20431

Telephone: (202) 623-7430 • Telefax: (202) 623-7201

E-mail: publications@imf.org • Internet: http://www.imf.org

\section{International Monetary Fund} Washington, D.C. 



\title{
INTERNATIONAL MONETARY FUND AND \\ THE INTERNATIONAL DEVELOPMENT ASSOCIATION
}

\section{UNION OF THE COMOROS}

\author{
Joint Staff Advisory Note on the Interim Poverty Reduction Strategy Paper \\ Prepared by the staffs of the International Monetary Fund \\ and the International Development Association \\ Approved by Thomas Krueger and Anthony Boote (IMF) \\ and Gobind Nankani (IDA)
}

May 2, 2006

\section{Overview}

1. The Government of Comoros transmitted its Interim Poverty Reduction and Growth Strategy Paper (I-PRSP) to the IDA and IMF on October 13, 2005, the first comprehensive economic and social strategy document elaborated through a wide participatory process. This Joint Staff Advisory Note (JSAN) is intended to provide feedback to the authorities on their poverty reduction strategy as they move to the preparation of the full PRSP.

2. The Union of Comoros has made significant progress with national reconciliation. The decade-long separatist crisis between the three islands has been largely overcome, and the new decentralized institutional architecture born out of the reconciliation agreement of December 2003 is formally in place. However, the political situation and inter-island relations are still fragile. The I-PRSP provides a long-term vision of sustainable economic growth and poverty reduction, which is considered critical for the consolidation of the national reconciliation process.

\section{Preparation of the I-PRSP and Participatory Process}

3. The I-PRSP was prepared through a broad participatory process launched in 2003 aimed at developing a national Poverty Reduction Strategy (PRS). The institutional structure consisted of: (i) an orientation committee on each island - composed of local authorities, representatives of civil society, and private sector organizations - whose main role was to mobilize stakeholders and provide guidance for the technical studies; (ii) a technical committee at the union level - composed of senior administration staff supported by representatives of civil society, private sector organizations, and national and international consultants - responsible for carrying out the work needed for preparing the strategy; and (iii) a coordination and monitoring committee - composed of the general commissar for planning, representatives from the islands' presidencies, and delegates from the orientation committees - responsible for oversight and validation. 
4. The PRS process created a consensual platform for communication and national cooperation in a period marked by tense relationships between the union government and island authorities. A first draft I-PRSP was produced taking into account the results of participatory workshops in May 2003, after which the process came to a virtual halt as political tensions reignited. The PRS process was revived in late 2004 following the December 2003 reconciliation agreement and the establishment of a more stable political environment. The draft 2003 I-PRSP was updated and complemented with an action plan for 2006-09. The documents were validated through additional broad consultative rounds, including workshops at the island levels.

\section{Poverty Diagnostic}

5. The PRS draws on a broadly adequate quantitative and qualitative poverty diagnostic derived primarily from comprehensive household surveys conducted in 1995 and 2004. The I-PRSP estimates that for the country as a whole, 37 percent of households - or about 45 percent of the population - live below the poverty line (estimated at about 285,000 Comorian Francs or about $\$ 700$ per capita per year). The incidence of poverty varies across islands and is generally higher in rural areas. The analysis also shows that inequalities in per capita expenditures increased substantially between 1995 and 2004, partly reflecting variances in inflows of remittances from the Diaspora.

\section{Core Elements of the I-PRSP}

6. The I-PRSP provides a comprehensive analysis of economic and social conditions in the country. It highlights key constraints on economic development and poverty reduction, including high population density, political instability, weak governance and institutions, fragile public finances, an underdeveloped financial system, poor infrastructure, lack of adequate resources for public health and education, and environmental challenges. The I-PRSP recognizes that achieving significant poverty reduction will require (i) sustained economic growth, (ii) improved human capital development, and (iii) improved governance and political stability. To achieve these objectives, the PRS comprises seven core strategic axes:

(1) Establishing supportive conditions for sustainable economic development by strengthening public finances and developing the country's infrastructure.

(2) Promoting private sector growth, with a particular emphasis on tourism, agriculture, and fishing.

(3) Strengthening the justice system and promoting good governance.

(4) Improving health conditions, with a particular focus on combating priority diseases, improving maternal health, and improving health system management.

(5) Promoting education and vocational training.

(6) Promoting a healthy and sustainable environment.

(7) Strengthening security and combating crime. 
7. $\quad$ The I-PRSP delineates 35 programs along these axes for the period 20062009 , with an annual average cost of about \$100 million (over 20 percent of GDP), the bulk of which would be financed through international aid. The staffs welcome this comprehensive and ambitious strategy, which provides a long-term vision for Comoros and sets clear objectives. The I-PRSP and related action plan are more comprehensive than what is usually expected and they contain most of the material required for a full PRSP. Going forward, it will be important to translate the strategy into near-term specific priority actions that are consistent with implementation capacities and the anticipated financial resources. This will require some further prioritization between the strategic axes and sectors. The staffs also believe that more work will be required in addressing implementation risks and strengthening monitoring systems. The following sections provide suggestions for strengthening key elements of the PRS.

\section{Macroeconomic and Structural Policies}

8. The I-PRSP's macroeconomic framework is broadly in line with the government's objectives of improving opportunities and living conditions for the poor. It envisages higher real GDP growth, continued low inflation, higher social spending, and an ambitious medium-term public investment program. The full PRSP could develop the medium-term macroeconomic framework more fully, including by developing alternative scenarios for GDP growth and underlying sectoral performance. There should be a clear link between priority programs under the PRS and the medium-term budgetary framework, taking into consideration the availability of external financial assistance and debt relief under different scenarios. In this context, it will be important to consider potential downside risks, such as shortfalls in aid disbursements, delays in implementing reforms, or balance of payments shocks, and to develop appropriate contingencies.

9. In the area of fiscal policy, the I-PRSP envisages the simplification and harmonization of tax policies and the strengthening of tax administration to ensure an adequate level of resources. These policies should secure an increase in the domestic revenue-to-GDP ratio during 2006-2009. With public administration spending under strain from the demands of a decentralized government system, the scope for expenditure reallocation within the existing resource envelope appears limited. Any significant increase in social spending and growth-oriented investment would therefore have to be achieved with external support. Most of this support should be in the form of grants, given Comoros' unsustainable external debt situation. In this regard, it will be important to improve public management procedures, control costs, and enhance allocation decisions so that donor funds will be put to effective use. The authorities could elaborate on priority reforms in the areas of revenue administration and public management in the full PRSP, taking into account ongoing technical assistance and the experience with decentralized public finances since 2004. The full PRSP should discuss Comoros' strategy for resolving its large external debt burden, including prospects for debt relief under the enhanced HIPC initiative and MDRI.

10. The I-PRSP rightly stresses the need to foster private sector development and good governance to achieve equitable economic growth and employment creation. Improving the business environment, in particular business legislation and the judicial 
environment, is deemed essential to attract foreign investment and improve access to bank financing. The I-PRSP also appropriately highlights the importance of developing the country's infrastructure and the financial sector. The staffs believe that the private sector and civil society have a crucial role to play in achieving these objectives. The full PRSP could usefully explore mechanisms for enhancing private sector participation in infrastructure provision, environmental protection, and in the health sector.

11. The I-PRSP identifies key growth sectors - notably agriculture, fisheries and tourism - that have the potential to generate sustained economic growth. While the focus on these sectors is generally consistent with the objectives of the PRS, more preparatory work will be needed in the formulation of specific policies. In particular, the staffs believe that public policy should be focused on providing an enabling environment for private sector development and international trade, while avoiding production subsidies. The recent shift from high import tariffs to indirect taxation and Comoros' entry into COMESA's free trade zone have been steps in this direction. In other areas, further analytical work will be needed to ensure the economic and environmental sustainability of the I-PRSP's policies. In fisheries, for example, the envisaged transformation of traditional coastal fishers into off-shore fishers (by promoting motorization, shore-based infrastructure, and joint-ventures) could lead to overexploitation of coastal resources. More generally, the staffs consider that the envisaged resources for promoting the key growth sectors identified in the I-PRSP appear high relative to other priority areas such as governance, health, education, and sustainable water management. It would also be useful, in the context of the full PRSP, to address the risk of shocks and ways of mitigating them, drawing on the recent experience in the vanilla sector.

\section{Human Development}

12. The staffs welcome the I-PRSP's emphasis on human development, in particular the designation of health and education as two priority areas and the envisaged increase of public spending in these areas. The human development section of the I-PRSP sets out an appropriate and ambitious strategic direction for the long term. The staffs recommend that the authorities prioritize and specify intermediate steps under the strategy, focusing on a realistic action plan based on available resources. Implementation should include the identification of basic indicators and a clear data collection strategy. The staffs also recommend that the government focus initially on delivery of basic services targeted at the poor. The full PRSP could usefully discuss the link between the main objectives under Comoros' PRS and the Millennium Development Goals (MDGs).

13. The education strategy aims to address the challenge of expanding school attendance and quality in the context of rapid population growth and very limited resources available for education. Despite progress in recent years, enrollment rates at the primary and secondary levels continue to be low and marked by gender disparity. Delays in paying teachers' wages and limited budget allocations for primary education are among the key constraints. The staffs recommend that the authorities focus on primary education as the principal priority while gradually developing other levels, such as higher education and vocational training, as more resources become available. The monitoring indicators for education could be expanded to reflect public expenditures in education. 
14. The health sector strategy outlines reasonably well the advantages and institutional responsibilities of the public health system. The strategy identifies access to basic services as the critical challenge for Comoros, and explicitly mentions reproductive health, malaria, and malnutrition as priority programs. The staffs fully agree with this assessment and recommend that the authorities focus their efforts on addressing key constraints, including the lack of qualified health personnel, the poor maintenance of existing medical equipment, and the bottlenecks in the pharmaceutical sector that result in high cost and limited availability of medicines. The authorities' health sector objectives are ambitious and the PRS would benefit from the specification of clear priority actions and the sequencing of reforms. The staffs also consider that more work will be required in the specification of the health indicators and medium-term targets.

\section{Implementation and Monitoring Mechanisms}

15. Effective implementation of the PRS will require significant improvements in the country's statistical capacity, in particular more comprehensive and detailed expenditure tracking procedures than are currently in place under the existing budget accounting system. At present, the accumulation of budgetary arrears makes it difficult to track budget execution and expenditures on specific programs, severely constraining donors' ability to provide effective assistance. These problems are compounded by the decentralization of budgetary authority. A similar lack of reliable and timely data applies to most other economic and social indicators. The staffs welcome the authorities' intention to improve expenditure monitoring and the collection of other economic and social indicators in the context of the PRS, and note that building statistical capacity will require substantial technical assistance. The staffs also recommend that the authorities clarify the roles and responsibilities of each data-producing agency within a new institutional setting that ensures effective cooperation between all parties.

\section{Conclusion}

16. The Bank and Fund staffs believe that Comoros' I-PRSP is in line with the needs of a country that has emerged from a long-lasting national crisis and is aiming at sustained economic growth and poverty reduction. The staffs welcome the broad participatory process in which the document was prepared and believe that the I-PRSP and the related action plan already contain most of the elements necessary for a full PRSP. As discussed above, priority areas for further strengthening the PRS process and compiling a full PRSP include:

- Specifying short-term priority actions consistent with implementation capacities and the anticipated external assistance, based on a further prioritization of resources across strategic axes and sectors;

- Developing the macroeconomic framework more fully, including by clearly linking priority programs under the PRS to the medium-term budgetary framework, taking into consideration the availability of external financial assistance and debt relief under different scenarios; 
- Strengthening revenue administration and budget management systems, and establishing comprehensive and detailed expenditure tracking procedures;

- Strengthening the analysis of sectoral policies, including for fisheries, and exploring options for enhancing private sector participation in infrastructure, the environment, and health;

- Linking the objectives of Comoros' PRS with the MDGs;

- Strengthening the statistical capacity, including by clarifying the roles and responsibilities of each agency; and

- Identifying key implementation risks and related contingencies.

17. The authorities have acknowledged the need for further work in these areas and have called on the donor community to help Comoros strengthen the PRS process. In particular, they have requested a second PRSP Trust Fund grant aimed at strengthening their poverty analysis and monitoring capabilities, while sharpening the analysis in specific areas to allow better prioritization of the policy actions identified in the I-PRSP. The staffs believe that capacity enhancement of public institutions will be critical for the successful implementation of the PRS and will require significant external financial and technical assistance.

18. Executive Directors' views are sought on whether they agree with: (i) the broad directions of PRS of the Union of Comoros; (ii) the priority areas identified by the staffs for strengthening the PRS process and moving towards a full PRSP. 